\title{
Behavioural Ecology in Traditional Societies
}

\section{Monique Borgerhoff Mulder}

Can models from behavioural ecology explain cultural diversity in Guman populations? Studies of variation in reproductive and productive behaviour, both within and between traditional societies, are beginning to show that specific predictions from sexual selection and optimal foraging theory can be developed and tested with human data. Greatest success has been in the study of foraging; whereas attempts to understand patterns of marriage and parental investment have been most convincing in those cases where behaviour is related to specific ecological and social conditions. The aim of human behavioural ecologists in the future will be to determine the constraints that the dual goals of reproduction and production place on individuals.

Over the last fifteen years, an exciting new field known variously as 'human sociobiology', 'evolutionary biological anthropology' and 'human behavioural ecology' has been growing fast. Under its first name, human sociobiology has often been equated with the explicit genetically based model of kin selection; but such characterization is incorrect. This new field is concerned with much more than the study of nepotism in traditional populations. In essence, it aims to develop and test specific models that account for behavioural variability observed within and between different human populations, on the assumption that people learn to adopt different behavioural patterns in different ecological and social contexts such that their behaviour maximizes their inclusive fitness. From the outset, then, concepts from optimal foraging theory and sexual selection have played as critical a role in developing hypotheses as have those from the theory of kin selection: specifically, the study of life history variation, reciprocal altruism, sex-biased inheritance, cooperative breeding and evolutionary stable strategy are emerging as key foci of interest.

Monique Borgerhoff Mulder is at the Evolution and Human Behavior Program, Rackham Building, University of Michigan, Ann Arbor, Ml 48109-1070, USA
In this review, I document the growth and scope of behavioura ecology in its application to human behaviour and suggest where the future of this exciting new approach to the study of human culture may lie. I focus exclusively on research conducted in traditional and historical populations in relatively underdeveloped parts of the world since studies of adaptation in modern industrial contexts entail a number of assumptions that are difficult to meet ${ }^{1}$. I concentrate on sound empirical research rather than dwell on weaker speculative work, for which detailed conceptual and methodological critiques have already appeared ${ }^{2,3}$.

The rate at which empirical papers have appeared is shown in Fig. 1; they now amount to 163 publications. Two highly influential volumes appearing in 1979 and 1981, by Chagnon and Irons ${ }^{4}$ and Winterhalder and Smith ${ }^{5}$ respectively, sparked off an interest among anthropologists in the relevance of natural selection to the study of human behaviour. Among these studies a principal distinction can be drawn between studies of reproduction and those of foraging (Table 1), with the former growing primarily from evolutionary genetics and the latter from evolutionary ecology ${ }^{6}$. Although studies of reproduction are more numerous (113) than those of foraging (50), both fields have been central to the growth of human behavioural ecology. If analyses of archaeological and paleontological material were included, studies of foraging land related issues of spatial organization and food sharingl would equal those of reproduction 7,8 .

\section{Reproductive competition in men and women}

Although many different areas of human reproductive behaviour have been examined from an evolutionary perspective, intra-male competition has been most studied (Table 1). Individual differences in wealth, power, religious position, hunting skill, violence and conformity have all been shown to con- tribute to high male reproductive success in different societies, largely through enhanced access to

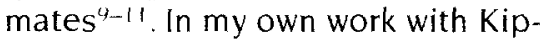
sigis, agro-pastoralists of Kenya, men are shown to be concerned with not only the quantity 12 but also the quality of their mates. in that they make particularly high marriage payments for brides of high reproductive value. as measured by a woman's age at menarche ${ }^{13}$. Intense intra-male competition is now well documented and has generated interesting predictions about sexspecific inheritance in historical 14,1 and traditional societies ${ }^{10}$

Reproductive competition among women has been studied less, but intense conflict can occur. For example, in rural Trinidad, Flinn finds that women in households in which two reproductive-aged women Igenerally mother and daughter co-reside have lower fertility than women in households containing single reproductive females; some evidence suggests this may be linked to high agonistic interactions among women within households Evidence that labour stress may limit women's reproduction comes from Turke's study on lfaluk, a Micronesian atoll. There, as in many traditional societies, daughters help their mothers considerably in child care, with the result that mothers who produce daughters first enjoy longer and more successful reproductive careers than those who produce sons first ${ }^{18}$, suggesting an element of 'cooperative breeding ${ }^{19}$. In other societies, such as the Kipsigis, access to resources is more critical to successful reproduction than is access to labour? ${ }^{n}, 1$ found that women appear to choose their spouses with respect to the man's wealth rather than his current marital status ${ }^{21}$, as the polygyny threshold model would predict ${ }^{22}$ (Fig. 2).

\section{Reproductive strategy and variability in human breeding systems}

A salient question to arise from empirical studies such as these is what accounts for the ethnographic diversity, only hinted at here, in breeding patterns. For example. what are the direct ecological correlates of the intensity of male competition? In 1979 Dickemann pro- 
posed that extreme environmental instability (drought, famine, war, plague and all the social upheavals thereby engendered $\mathrm{l}$ is associated with high levels of polygyny ${ }^{23}$. Ihere has been no systematic test of this hypothesis yet, although there is a significant relationship between unpredictability of rainfall and the cross-cultural occurrence of polygyny (B. Low, unpublished). Betzig suggests that large harems may be particularly prevalent in populations that are circumscribed by geographic or social barriers (mountains or warring enemies), because men who fail to find wives are unable to leave physically and start a family elsewhere ${ }^{10}$; why subordinate males tolerate such reproJuctive inequality remains unanswered. To date, however, the strongest support for the importance of ecological constraints on luman breeding systems is Crook and Crook's description of how polyandry may be directly continsent on the scarcity of cultivable land in the arid Himalayan valleys of Ladakh; the only option for a second son is to share his brother's ivife 24

Evolutionary biological anthro pologists more commonly stress the social rather than the ecological correlates of polygyny ${ }^{25}$. For example, the number of relatives a man an call his allies, his manipulative kills and his reputation can be uritical in successful fights or negotiations over women, as Chagnon carefully describes for the largely horticultural Yanomamo Indians of Yenezuela20. Emphasis on the importance of competition with conspecifics should not, however, cletract attention from the role of cological factors in structuring krceding systcms. Indced it is perhaps only the richness of the yanomamo environment that enables a man to support large groups of co-resident kin with whom to raid and fight for women ${ }^{27}$. Furthermore, in more labourintensive productive systems, as among the K'echi Indian agriculturalists of southern Belize, Berte attributes the positive association between a man's reproductive siccess and the number of his ron-descendant kin in the local (i)mmunity to his success in swidden cultivation of maize, which is itself shown to be directly dependent on cooperative labour exchange among $\operatorname{kin}^{28}$. In short, while there are no systematic analyses of the incidence of polygyny across human cultures, resource distributions that enable some men to monopolize resources and/or labour for their own reproductive benefit are likely to be a key factor as in many other species ${ }^{29}$.

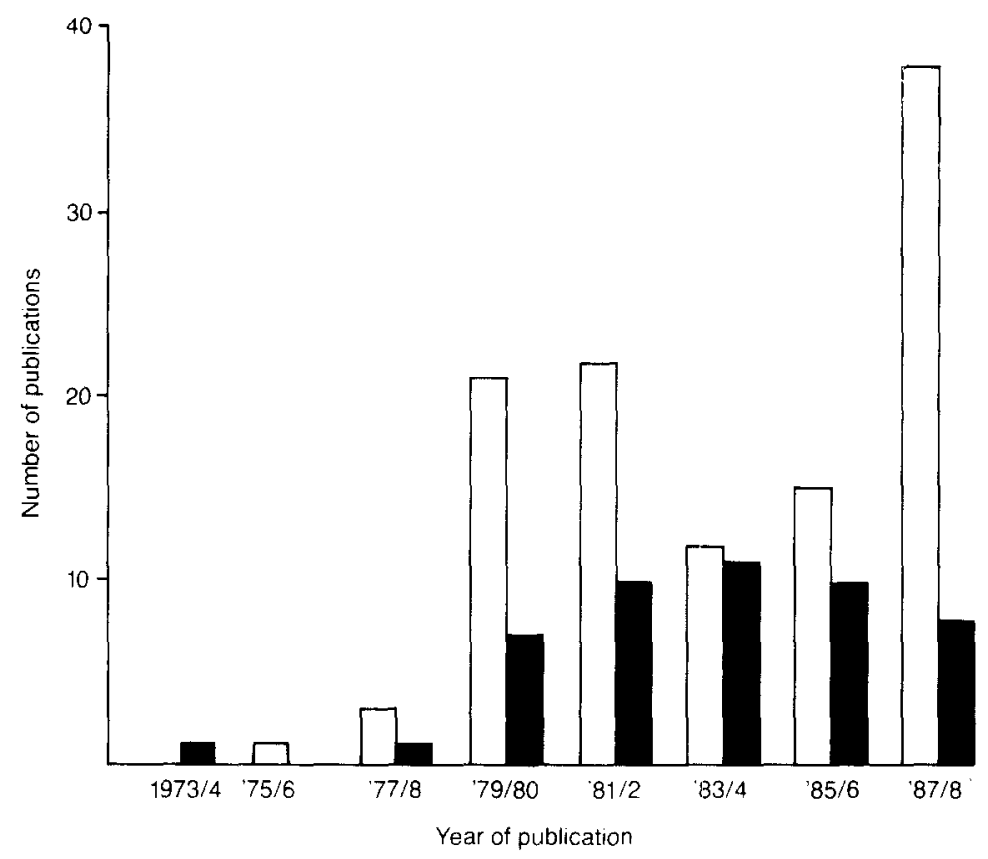

Fig. 1. Number of studies published in two year periods. White bars denote studies of reproduction. black bars studies of foraging. Data include all the empirical, quantitative studies I could find that explicitly address theories derived from evolutionary biological theory with data from traditional and historical societies in relatively underdeveloped regions. Review articles isuch as this onel and authored books are omitted, unless containing new analyses of quantitative data. Articles with confirmed 1988 publication dates are included. Bibliography can be obtained from the author.

\section{Foraging strategy}

Behavioural ecological anthropologists have begun to investigate diet breadth and group size, primarily among hunter-trapperfishers, hunter-gatherers and horticulturalists of the Americas. They adopt the models and methods of optimal foraging theorists, working from the assumption that humans select among behavioural alternatives so as to maximize net energy capture per unit time, measuring the costs and benefits in time and calories respectively ${ }^{30}$. Efficiency in energy capture is assumed to correlate with fitness ${ }^{31}$, as in all optimal foraging studies, although there has been some debate over whether humans are energy maximizers or time minimizers.

\section{Foraging and optimal diet breadth}

Which resources should an efficient forager harvest? The optimal diet breadth model states that, if resources are randomly encountered, an item will be taken only if the net energy return per unit handling time is greater than the average return rate, including search time, of all prey types of higher rank ${ }^{32}$. For the Ache, Hawkes and her collaborators show that resource choice can be predicted from this model: all sixteen food resources exploited by men and women foragers during a four- month period were characterized by higher returns after encounter than overall Ache foraging returns ${ }^{33}$. Diet breadth and patch size models, the latter not assuming a random distribution of prey, also predict the resources taken by the Alyawara Aborigines of Australia, including the recent exclusion of seeds from their diet ${ }^{34}$.

Hames and Vickers examine how

\begin{tabular}{|lc}
\hline \multicolumn{2}{|c}{ Table 1. Studies by central topic } \\
\hline \multicolumn{1}{|c}{ Topic } & $\begin{array}{c}\text { Number of } \\
\text { Publications }\end{array}$ \\
\hline & 113 \\
Reproductive strategy and & \\
mating systems & 36 \\
Male competition & 27 \\
Investment in offspring & 15 \\
Kin selection & 14 \\
Parental care & 11 \\
Life history studies & 5 \\
Female fitness & \\
determinants & 5 \\
Sexual dimorphism & \\
Foraging studies & 50 \\
Diet breadth & 33 \\
Spatial organization and & 12 \\
group size & \\
Food sharing and & 5 \\
reciprocity &
\end{tabular}

a Sources of data as in Fig. 1. 


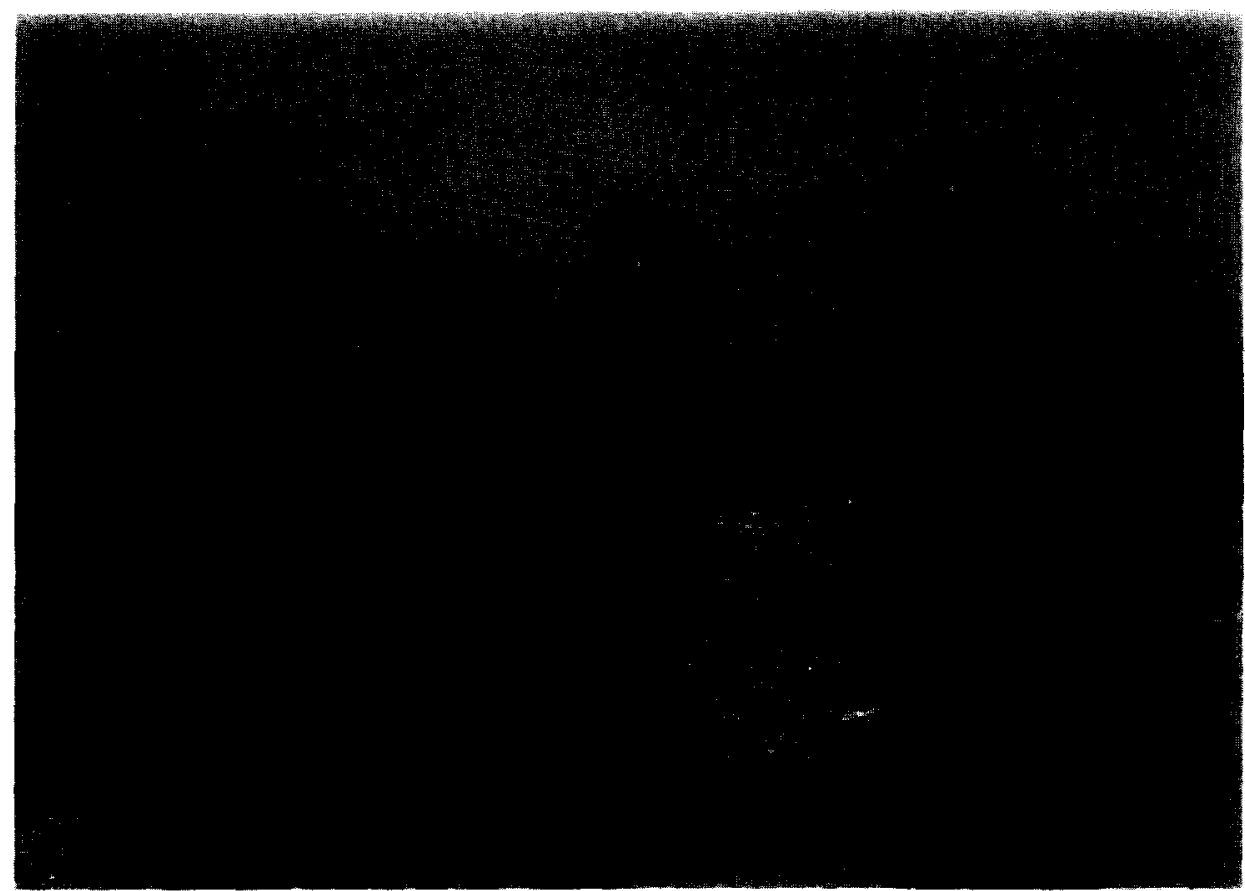

Fig. 2. Does the polygyny threshold model apply to pastoralists of East Africa? Polygynously-married wives collecting water: the Tatog of Tanzania. Photo by Monique Borgerhoff Mulder.

game depletion and technology affect species' ranking, and hence what is taken ${ }^{35}$. Diet breadth increases in relation to settlement age among the Siona-Secoya In-
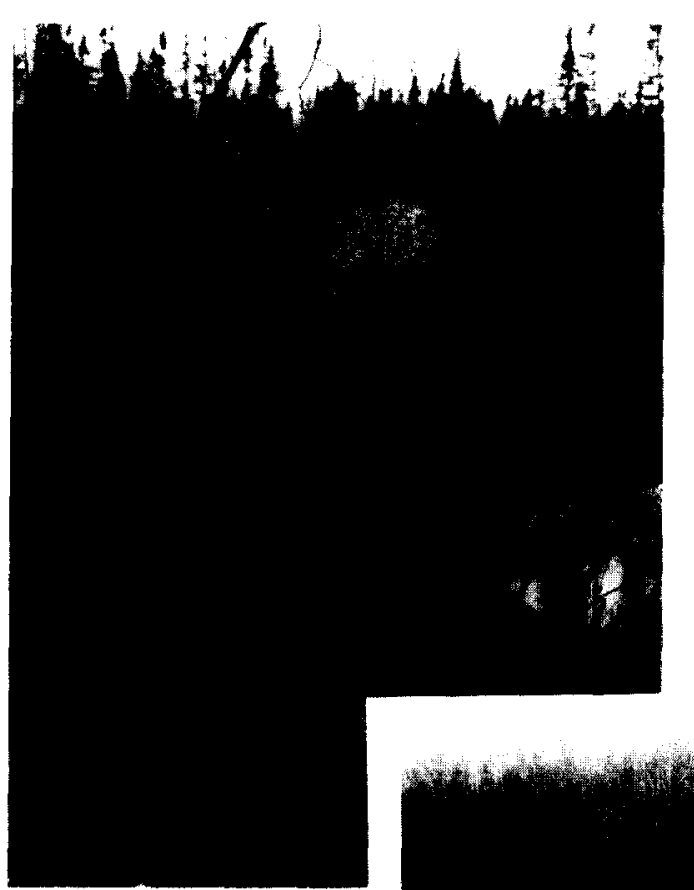

Fig. 3. Cree toragers in the Canadian subarctic use modern technology in the quest for food, but their hunting and tactics date from earlier periods and often match those predicted by foraging theory models Photos by Bruce Winterhalder. dians of Amazonian Equador, as the high-ranked species become scarce and difficult to hunt and hunters become less specialized; furthermore efficiency increases and diet breadth declines, as people hunt further from their settlements, as shown for the Siona-Secuya, the Yanomamo and their Ye'kwana neighbours 35 . Winterhalder shows how technological innovations that decrease search time constrict diet breadth: with snowmobiles, the boreal forest Cree Indians of northern Ontario can afford to ignore lower-ranked game and specialize on moose, beaver, hare and fish ${ }^{3 t}$ (Fig. 3). Finally, guns that increase the pursuit efficiency of some Ache men, lead to lower-ranked species such as monkeys being disregarded ${ }^{37}$, although not among the Yanomamo and Ye'kwana ${ }^{55}$. Clearly the effects of hunting technology on diet breadth will depend on prey distributions, how they are hunted and the relative importance of search to pursuit time in hunting 35,30 . Anthropologists are now beginning to examine other factors associated with resource choice: sex differences in resourcegathering efficiency and opportunity costs 31,38 , the costs of tool maintenance ${ }^{3.4}$, the optimal strategies of others $(K$. Hawkes, unpublishedl, specific nutrient needs 31 and risk aversion (B. Winterhalder. unpublished). Issues still largely unsolved include the tabooing of certain game items and the distribution of hunting technology, such as blowpipes and bows in the Amazon.

\section{Foraging, group size and settlement patterns}

Why do humans invariably live in groups larger than the nuclear family? Behavioural ecologists are starting to determine the selective factors operating on group formation and size. Focusing on hunting, Sinith's study of the Inuit Indians of Hudson Bay shows that observed pursuit groups in different types of hunts le.g. goose, beluga whales, ptarmigan I are generally larger than that which would maximize individual returns and smaller than that which would maximize group returns ${ }^{34}$. Similarly, Ache hunters call for help after encountering monkeys and coatis, even though individual returns are greater when hunting these species alone ${ }^{37}$ Clearly, pursuit groups are not of optimal size, as measured by energy returns either to the individual or to the group. In an innovative attempt to tackle the unsolved question of optimal pursuit group size, Smith assesses some of the social constraints on pursuit group formation, such as relatedness rules for sharing the kill and conflicts among 'members' and 'joiners' using Inuit data ${ }^{\circ}$. The importance of constraints on movement and information-sharing remain largely unexamined, as in other species.

Pursuit efficiency seems only to set the lower size limits of residential groupings. Blurton Jones ${ }^{40}$ proposes one reason why food sharing groups may be larger than the optimal pursuit group size, in 
troducing the concept of 'tolerated theft': he suggests that the costs of continued defense of a food resource with a diminishing fitness return curve will far exceed the benefits, leading (under some conditions) to the formation of larger groups than required for efficient food acquisition. Physical defense may be another important factor: the largest Yanomamo villages are cound in areas where there is most inter-village warfare ${ }^{41}$

Finally, in less bellicose societies, esidential units may be maintained oy the need for communal labour in seasonal or fluctuating environnents and in economies of scale where individual efficiency is sreater in a group than alone ${ }^{42}$. Although there are some exciting comparative studies of the effects of resource predictability and density on human patterns of settlement and exchange ${ }^{43-45}$, testing models for the distribution of erritoriality ${ }^{40}$ and central place foraging ${ }^{47}$, little is yet known of the determinants of the size and stability of human settlements. This is a question that deserves priority of investigation, given modern nations' interference with traditional land rights and the effects on subsistence, ranging and settlement.

\section{Integrating studies of subsistence and reproduction}

Suddenly a wealth of empirical evinence is pouring into a field once characterized as idle speculation and 'just-so' story telling. The future of behavioural ecology of traditional societies must lie in an integration of studies of reproduction and foraging ${ }^{6,29,31}$. Since the ultimate 'goal' of any organism is to maximize fitness, it becomes necessary in studies of foraging to determine the fitness consequences of energy capture Similcrly, studies of reproduction must assess the fitness gains associated with reproductive and social activities that compete with foraging for $a \mathrm{n}$ individual's time.

Rather remarkably, studies in tiuman behavioural ecology are at the forefront in investigating such trade-offs between production and reproduction, perhaps because vith advanced technology humans are less critically energy-limited than many other species. As evolitionary biological anthropologists recognize that variations in time allocated to different activities in different subsistence types probably reflect differences in fitness benefits and opportunity costs as much as in net energy returns, they are starting to examine the constraints of foraging (essentially food production I on reproduction land vice versal and how different trade. offs between these activities are reached. Thus, for example, Hawkes, Hill and Kaplan's finding that good Ache hunters hunt for more hours than do poor hunters and still consume significantly less of their own meat than do others seemed anomalous until the reproductive benefits (extramarital matings) of being a reliable meat provider were shown ${ }^{48}$. In a similar vein. Bailey argues that specialization in foraging for honey and meat among male Efe pygmies of the Ituri Forest in Zaire is primarily a strategy for forming important political liaisons with their agricultural Lese neighbours ${ }^{49}$.

Trade-offs between foraging and reproduction have also been determined for women. Blurton Jones examines how the birth intervals of !Kung women, who carry their babies while gathering mongongo nuts over large daily ranges in the intense heat of the Kalahari, vary according to parity, family size and degree of dependence on gathered foods. A quantitative model shows that spacing births at 4-year intervals precisely reduces a woman's nut and baby load to that which will support the family without threatening women with thermal exhaustion ${ }^{50}$. Among the Ache where foraging is less energetically demanding, women have shorter birth intervals (Fig. 4); furthermore. Ache women with dependent un weaned offspring can reduce their foraging effort compared with that of other women ${ }^{38}$, perhaps because men supply nearly $90 \%$ of the calories eaten by the whole group 33,48 . Such studies of the ecology of reproduction and parental care should play a pivotal role in future studies of human behavioural adaptation, as suggested by Irons $^{51}$. Clearly however, for human behavioural ecology to rival that of non-humans, many more studies are needed: this review was based on work conducted in just sixteen traditional societies.

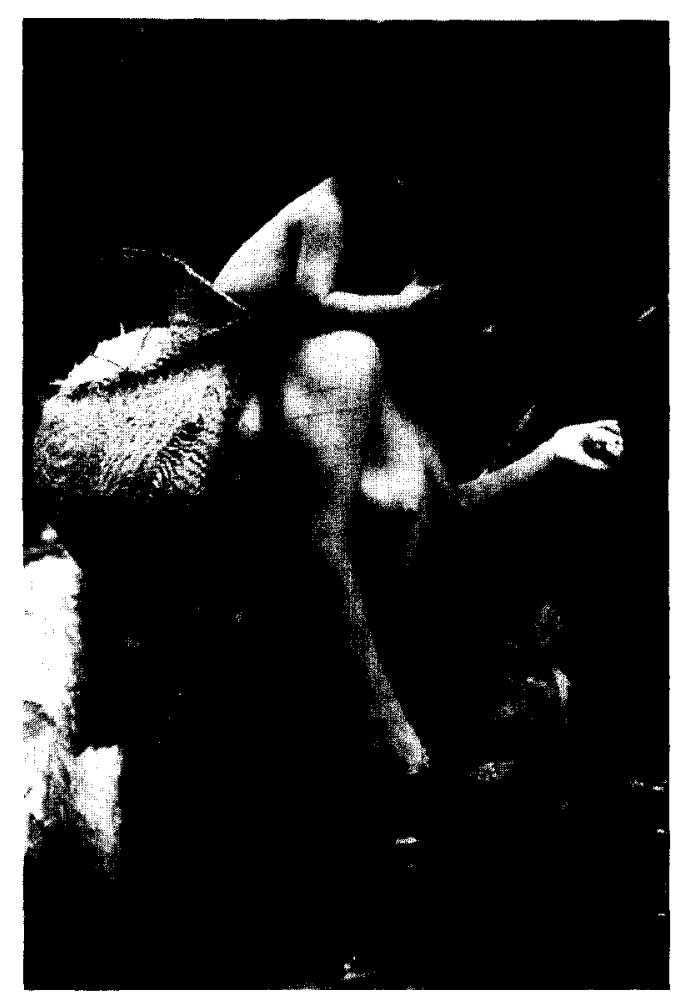

Fig. 4. Ache woman forages with her child (Paraguay) Photo by Department of Anthropology, University of utah.

Acknowledgements

Tim Caro, Kristen Hawkes, Dan Sellen and Daniela Sieff commented on earlier drafts of this manuscript; many others helped with references and discussion, and Iudy Maas with the typing. Thanks to you all.

\section{References}

1 Caro, T.M. and Borgerhoff Mulder $M$ (1986) Ethol Sociobiol. \&. 61-72

2 Kitcher, P. 119851 Vaulting Ambition. MIT Press

3 Gray, P.J. 119851 Primate Sociobiology, HRAF Press

4 Chagnon, N.A and Irons, W. eds 19791 Evolutionary Biology and Human Social Behaviour, Duxbury Press

5 Winterhalder, B.A and Smith, E $\wedge$. eds, (1981) Hunter-Gatherer Foraging Strategies, University of Chicago Press

o Smith, E.A. (1985) Ethol Sociobiol 0, 27-47 7 Beddinger, R.L. 119871, Annu. Rev

Anthropol. 16, 121-142

8 Foley, R. (1986) Another Unique Species. Longmans

9 Irons, W. 119791 in Evolutionary Biology and Human Social Behavior (Chagnon. N.A. and Irons, W.. eds), pp. 252-272, Duxbury Press

10 Betzig, L.L. (1980) Despotism and Differential Reproduction, Aldine 11 Chagnon, N.A. 119881 Science 239 985-992

12 Borgerhoff Mulder, M. $119871 \mathrm{Am}$. Anthropol. 89, 617-034

13 Borgerhoff Mulder, M. 11988 in Human Reproductive Behaviour (Betzig, LL. Borgerhoff Mulder, M. and Turke, P.W., eds), pp. 65-82, Cambridge University Press 14 Boone, I.L. III (1988) in Human Reproductive Behaviour (Betzig, L.L. Borgerhoff Mulder, $M$. and Turke, P.W., edsI pp. 201-219, Cambridge University Presa 15 Voland, E. 119881 in Comparative Socioecology of Mammals and Man iStanden, V. and Foley, R. edsi. Blackwell 
16 Borgerhotf Mulder. M.119881 in Comparative Socioecology of Mammals and Man (Standen, V. and Foley R. eds). Blackwell

17 Flinn, M.V. 11988 in Sexual and Reproductive Strategies (Rasa, A., Vogel. C and Voland, E., eds), Croum Helur

18 Turke, P.W. 119881 in Human

Reproductive Behaviour (Betzig, L.L., Borgerhotf Mulder, M. and Turke, P.W. edst. pp. 173-188, Cambridge University Press 19 Emlen. S.T. 11984$)$ in Behavioural Ecology (Krebs, I.R. and Davies, N.B., eds), pp. 305-339, Blackwell

20 Borgerhoff Mulder. M.|1987।/. Zool. 213 489-505

21 Borgerhoff Mulder. M. (1988) in Reproductive Success (Clutton-Brock, T.H., ed.I, Chicago University Press

22 Orians. G.H. (1909) Am. Nat. 103, 589-003

23 Dickemann, M. (1979) in Evolutionary

Biology and Human Social Behaviour

IChagnon, N.A. and Irons, W., eds), pp.

32!-367, Duxbury Press

24 Crook, I.H. and Crook. S.J. 119881 in Human

Reproductive Behaviour (Betzig, L.L.

Borgerhoff Mulder, M. and Turke, P.W. eds।

pp. 97-114, Cambridge University Press

25 Flinn. MV and Low B.S 119861 in

Ecological Correlates of Social Evolution

(Rubenstein. D.I and Wrangham, R.W., eds)

pp. 217-243. Princeton University Press

26 Chagnon, N.A. 119881 in Human

Reproductive Behaviour Betzig. L.L.
Borgerhott Mulder. M. and Turke, P.W., edsi. pp. 23-48, Cambridge University Press 27 Chagnon, N.A. (1979) in Evolutionar Biology and Human Social Behaviour IChagnon, N A and Irons, W., edsI. pp 374-401, Duxbury Press

28 Berte, N. 119881 in Hunln Reproductive Behaviour (Betzig. L.L., Borgerhoff Mulder M. and Turke, P.W., edsi. pp. 83-96 Cambridge University Press

29 Rubenstein, D. I and Wrangham, R.W 119801 Ecological Correlates of Social Evolution, Princeton University Press 30 Smith, E.A.11983) Curr. Anthropol. 24, 6.) $5-640$

31 Hill K Kaplan $H$. Hawkes, K and Hurtado, A.M. 11987 I Ethol Sociobiol 8. 1-30 32 Charnov, E.L. 119761 Am. Nat. 109, 343-352 33 Hawkes, K. Hill, K. and O'Connell, I 119821 Am. Ethnol. 9, 379-398

$34 O^{\prime}$ Connell. I. and Hawkes, K. 119811 in Hunter-Gatherer Foraging Strategies IWinterhalder, B. and Smith, E.A., edsI, pp 99-125, University of Chicago Press 35 Hames, R.B. and Vickers; W.T. 119821 Am Ethnol 9,358-378

36 Winterhalder, B. 119811 in HunterGatherer Foraging Strategies (Winterhalder. B. and Smith, E.A., edsI, pp. 00-98, University of Chicago Press

37 Hill, K. and Hawkes, K. 119831 in Adaptive Responses of Amazonian Indians II lames. R.B. and Vickers, W.T., edsi. pp 139-188, Academic Press
38 Hurtado. A.M. Hawkes. K. Hill. D. and Kaplan, H. (1985) Hum. Ecol. 13, 1-28 39 Smith. E.A. 119811 in Hunter-Gatherer Foraging Strategies (Winterhalder, B. and Smith. E.A. edsl. pp. 30-65. University of Chicago Press

40 Blurton Iones, N.G. 119841 Ethol

Sociobiol. $5,1-4$

41 Chagnon. N.A. 119741 Studying the Yanomamo, Holt, Rinehart and Winston 42 Hames, R. $\{1987$ ) Ethol Sociobiol. 8 259-284

43 Dyson Hudson. R and Smith F A. 11978 Am. Anthropol 84, 21-41

44 Cashdan, E. 119831 Curr Anthropol 24

$47-60$

45 Kaplan, H. and Hill, K. 119851 curr Anthropol 20, 223-240

46 Brown, I.L. (1904) Wilson Bull. $70,100-100$ 47 Horn, H.S. 119081 Ecology 49, 082-69.4

48 Hill, K. and Kaplan. H. 19881 Human Reproductive Behaviour (Betzig. L.L. Borgerhoff Mulder, M. and Turke, P.W.. edsl. pp. 277-289. Cambridge University Press

49 Bailey. R.C. 119881 in Diet and Subsistence: Current Archaeological Perspectives (Kennedy, B.L. and LeMoine G M ed.I pp. 57-65. University of Calgary 50 Blurton lones, N. 11987 Ethol Sociobiol $8,183-203$

51 Irons. W. 19831 in Social Behavious of Female Vertebrates (Wasser. S ed I pp 109-213. Academic Press

\section{Projection Matrices In Population Biology}

\section{Jan van Groenendael, Hans de Kroon and Hal Caswell}

Projection matrix models are widely used in population biology to proiect the present state of a population into the future, either as an attempt to forecast population dynamics, or as a way to evaluate life history hypotheses. These models are flexible and malhemalically relalively easy. They have been applied to a broad range of plants and animals. The asymptotic properties of projection matrices have clearly defined biological interpretations, and the analysis of the effects of perturbations on these asymptotic properties offers new possibilities for comparative life history analysis. The connection between projection matrix models and the secondary theorem of natural selection opens life cycle phenomena to evolutionary interpretation.

Ian van Groenendael is at the Department of Vegetation Science. Plant Ecology and Weed Sci ence, Agricultural University, Bornsesteeg 69,6708 PD Wageningen, The Netherlands: Hans de Kroon is at the Department of Plant Ecologv. University of Utrecht, Lange Nieuwstraat 100, 3512 PN Utrecht The Netherlands; and $\mathrm{Hal}$ Caswell is at the Biology Department, Woods Hole Oceanographic Institution, Woods Hole, Massachusetts 02543, USA.
Projection matrix models are an increasingly popular tool for describing population dynamics. They have been applied to a wide array of demographic problems Ivegetative propagation', predator-prey interactions ${ }^{2}$, competition ${ }^{3}$, two-sex populations", weed control ${ }^{5}$, patch dynamics ${ }^{6}$, bud dynamics on trees ${ }^{7}$. density dependence ${ }^{8}$ / for a variety of species ranging from mites ${ }^{2}$ to whales ${ }^{9}$. Projection matrix models serve two main scientific purposes. First, they can be used in attempts to forecast population dynamics (e.g. of pest organisms ${ }^{2.10}$ ). Second, because properties of the model correspond to life history characteristics such as fitness and reproductive value, they can be used to evaluate the long term consequences of hypothetical changes in the life cycle. Our revicw focuses on the latter application.

The simplest projection matrix models are discrete, linear, time invariant functions that map the state of a structured population from one time to the next. The transition into the next state is assumed to depend only on the current state of the population. The entries in population projection matrix contain all necessary $d y$ namical information, summarizing the ways in which survival, growth development and reproduction change the composition of the population from one time to the next. In matrix notation this can be expressed as a simple multiplication:

$$
\mathbf{n}(t+1)=\mathbf{A n}(t)
$$

Here $\mathbf{n}$ is a state vector whose elements are the numbers of individuals in each recognized category, and $\mathbf{A}$ is a square, nonnegative matrix.

Part of the success of projection matrices is due to the flexibility of their mathematical formulation. One can choose almost any set of categories in which to classify individuals, any time step over which to evaluate transitions, and almost any complexity in transition pattern 'I. Data from which to estimate the parameters of the model are at least conceptually straight- 